\title{
UN NUEVO MANUSCRITO DEL GEÓGRAFO AZ-ZUHRİ EN MALLORCA
}

\author{
Por \\ JUAN IGNACIO SÁEZ CASTAN
}

Entre los 35 manuscritos árabes catalogados por Míkel de Epalza (1) en la Biblioteca March, de Palma de Mallorca, sólo uno es de tema geográfico. Se trata del número 31 , que aparece como una "descripción de ciudades, especialmente andaluzas».

Es un manuscrito sin título ni nombre de autor, al que falta el principio. Tiene 74 páginas, de $19 \times 14,5$ centimetros, en cada una de las cuales, excepto en la última, hay 29 líneas. Su escritura es magrebi, de factura descuidada, en tintas negra $y$ roja.

En la última página aparece el nombre del copista: Muhammad lbn Ahmad Ibn Husain Ibn Ahmad Ibn Mūsà As-Sa'îdi, y la fecha en que éste lo acabó de copiar: el último día del mes de Rabiï Al-'Awwal del año $1261 \mathrm{H} / 1845 \mathrm{~d}$. C.

Este manuscrito parecè una copia del Kitāb Al-Ŷac rāfiyya, del geógrafo andalusí Az-Zuhrī (siglo XII). Su esquema es idéntico al de éste, y el texto guarda un gran paralelismo, aunque presenta un gran número de fragmentos añadidos o suprimidos, y la mayoría de los nombres propios aparecen modificados.

El Kitāb Al-Ŷyacrăfiyya ha sido objeto del interés de muchos estudiosos. Muhammad Hadj-Sadok estudió el texto árabe, basándose en nueve manuscritos, con un estudio crítico sobre la obra y el autor, en el que incluye un resumen parcial del contenido (2).

Como ejemplo de utilización reciente de este texto en España, podemos citar a Miquel Barceló, autor de dos artículos (3) relacionados con Mallorca.

(1) EPALZA, Míkel de, "Catálogo de 35 manuscritos árabes de la Biblioteca March de Paíma de Maliorcan, Separata de Fontes Rerum Balearium, Fundación Bartolomé March, Palma de Mallorca, 1977

(2) HADJ-SADOK, Maḥamed, "Al-Zuhri Kităb Al-Djagrafiyan, Bulletin d'études arientales, XXI, Damasco, 1986. páginas $1-310$.

(3) BARCELÓ, Miquel, «Alguns problemes de història mallorquina sugerits per un text d'Al-Zuhrin, Recerques, 8 , Barcelona, 1978, pp. 27-49 
Recientemente ha aparecido la tesis doctoral de Dolors Bramón, que estudia el texto publicado por Hadj-Sadok, comparándolo con una traducción parcial castellana del siglo XIII (4).

Parece que está a punto de aparecer un artículo de $M$. Tolmacheva en la revista A/-Qantara, en el que se da noticia de otro manuscrito del Kitab Al-Yacrafiyya, conservado en Harvard.

El objeto de esta nota es dar a conocer la existencia de este manuscrito de la obra de Az-Zuhri.

(4) BRAMON, Dolors, Estudio de la versión castellana y de su original arabe de una Geografia Universal, Universidad de Barcelona, 9-11-1984. 